\title{
Avaliação da incorporação de cinzas provenientes de biomassa de caldeiras em amostras de cerâmica vermelha
}

As indústrias de cerâmica vermelha atualmente apresentam um papel relevante como receptoras de resíduos sólidos que tem como visão sua disposição final. Se for realizado de maneira criteriosa, esta incorporação pode permitir dar um destino ambientalmente correto para esses resíduos que, de outra forma, seriam depositados na natureza o que os tornariam fontes de poluição. A incorporação dos resíduos em cerâmica vermelha pode ser um método de atender os interesses das indústrias de cerâmicas vermelhas, lucratividade e benefício ao meio ambiente, com isso possibilita a elaboração de novos produtos tendo uma qualidade compatível com os produtos já existentes no mercado tradicional. Adicionando diferentes percentuais de cinzas de biomassa, $5 \%$; $10 \%$; $15 \%$ e $20 \%$, na massa argilosa utilizada para a preparação dos corpos de prova de cerâmica vermelha, após a queima dos corpos de prova os mesmos foram avaliados em relação às alterações que foram produzidas nas propriedades físicas e mecânicas da cerâmica após o acréscimo das cinzas. As propriedades físicas e mecânicas avaliadas foram: massa especifica aparente, absorção de água, retração linear e tensão de ruptura à compressão. Os resultados obtidos indicaram que a adição da cinza à massa cerâmica contribuiu para aumento da porosidade e, consequentemente, piora na qualidade da cerâmica.

Palavras-chave: Cinzas; Resíduos; Cerâmica Vermelha.

\section{Evaluation of the incorporation of boiler biomass ash in red ceramic samples}

The red ceramic industries currently play a relevant role as receivers of solid waste that have as vision their final disposition. If carried out in a judicious way, this incorporation may allow to give an environmentally correct destination for those residues that would otherwise be deposited in nature which would make them sources of pollution. The incorporation of the residues into red ceramics can be a method to serve the interests of the red ceramic industries, profitability and benefit to the environment, with which it allows the elaboration of new products having a quality compatible with the products already existing in the traditional market. Adding different percentages of biomass ash, $5 \% ; 10 \% ; 15 \%$ and $20 \%$, in the clay mass used for the preparation of the test pieces of red ceramics, after the burning of the specimens were evaluated in relation to the changes that were produced in the physical and mechanical properties of the ceramic after the addition of the ashes. The physical and mechanical properties evaluated were: apparent specific mass, water absorption, linear shrinkage and compressive rupture stress. The results indicated that the addition of ash to the ceramic mass contributed to increase the porosity and, consequently, worsen the ceramic quality.

Keywords: Ashes; Waste; Red Ceramics.

Topic: Engenharia da Sustentabilidade e Meio Ambiente

Reviewed anonymously in the process of blind peer
Received: 10/02/2019

Approved: 25/03/2019
Thamyres Venancio de Oliveira Araujo (iD

Instituto Tocantinense Presidente Antonio Carlos, Brasil

http://lattes.cnpq.br/8038692598692713

http://orcid.org/0000-0003-1861-2665

myres_25@hotmail.com

Antonio de la Caridad Batista Montes de Oca

Instituto Federal do Tocantins, Brasil

http://lattes.cnpq.br/6224973145941777

tonho72@yahoo.com

Angelo Ricardo Balduino (iD

Instituto Federal do Tocantins, Brasil

http://lattes.cnpq.br/8475669590774317

http://orcid.org/0000-0002-7082-2566

angelo@ifto.edu.br
Juan Carlos Valdés Serra (iD

Universidade Federal do Tocantins, Brasi

http://lattes.cnpq.br/0422938566456925

http://orcid.org/0000-0002-6203-2759

juancs12@yahoo.com.br
Referencing this:

ARAUJO, T. V. O.; OCA, A. C. B. M.; BALDUINO, A. R.; SERRA, J. C. V.. Avaliação da incorporação de cinzas provenientes de biomassa de caldeiras em amostras de cerâmica vermelha. Revista Ibero Americana de Ciências Ambientais, v.10, n.2, p.223-233, 2019. DOI: http://doi.org/10.6008/CBPC2179-6858.2019.002.0019 


\section{INTRODUÇÃO}

A cerâmica vem sendo utilizada desde a descoberta do fogo, feita de argila, era utilizada para a fabricação de recipientes de armazenamento. Para se obter recipientes resistentes e impermeáveis foi observado que se expor a argila e materiais inorgânicos a altas temperaturas, poderia se originar um material com as características desejadas, tornando-se assim a cerâmica um dos materiais que mais se resiste ao tempo (CALLISTER, 2007). A cerâmica pode ser produzida para finalidades artísticas ou industriais, sendo que no caso citado em primeiro na sua produção é considerado apenas o valor estético, já no caso das cerâmicas industriais são destinadas as áreas da engenharia. Devido as suas diversas áreas de atividades, a cerâmica industrial é dividida em vários segmentos, onde se encontra como principais os revestimentos cerâmicos, cerâmica branca, materiais refratários, vidro, cimento e cal, fritas e corante, abrasivos, isolantes térmicos, cerâmica de alta tecnologia e cerâmica vermelha (TEIXEIRA, 2002).

O aumento populacional no mundo ocorre cada vez mais rápido, dessa forma implica consequentemente na expansão da utilização de materiais industrializados. Para atender o aumento da demanda mantendo o baixo custo e a boa qualidade, é necessário se aprofundar cada vez mais em estudos de matérias-primas que possam incorporar de forma positiva as propriedades em geral de tais materiais. A cerâmica vermelha é um desses materiais que vem apresentando o aumento de sua utilização (LUCAS, 2008).

Os estudos de inertização de resíduos industriais na indústria de cerâmica vermelha buscam, cada vez mais, levar ao melhor reuso deles e na obtenção de produtos com melhor qualidade, seja por mudanças nas formulações das misturas, por melhorias no processo de fabricação ou em sua desenvoltura físicomecânica. A incorporação de cinzas na argila para fabricação de peças de cerâmica vermelha apresenta-se como um ingrediente gerador de consequências positivas em sua composição físico-mecânica (MENEZES, 2002).

O Brasil está entre os maiores produtores de óleo de soja e de biodiesel do mundo, resultando na geração de resíduos com grande capacidade de poluição ambiental. As áreas que forem contaminadas por esses tipos de resíduos podem sofrer danos irreparáveis a sua biodiversidade. Devido a esse problema as indústrias produtoras de óleo de soja e biodiesel, dele, fazem o possível para minimizar os impactos que possam causar ao meio ambiente. Os gerenciamentos dos resíduos provenientes desta indústria apresentam grandes potenciais e possibilidades de serem utilizados no mercado, possibilitando retornos econômicos (PARENTE, 2003).

As indústrias de cerâmica podem contribuir dando uma finalidade para uma boa parcela desses resíduos que são agressivos ao meio ambiente tornando-os não nocivos e vantajosos economicamente, nela podemos avaliar os efeitos causados nas propriedades físico-mecânicas dos corpos de prova de cerâmica vermelha com incorporação da cinza, proveniente da caldeira de biomassa, determinando-se o percentual máximo de cinzas que possa ser incorporado. 


\section{REVISÃO TEÓRICA}

A biomassa é definida como qualquer matéria bruta que tenha sua derivação de organismos que estiveram vivo recentemente, isto é em resíduos sólidos, sendo suas fontes de origem vegetal, animal, industriais e florestais. Assim, temos variadas fontes de biomassa voltada para fins energéticos utilizados para gerar formas alternativas de energia, como a lenha; resíduos agrícolas, industriais ou de parques e jardins e outros (FIGUEIREDO, 2012).

A biomassa se encontra presente na sociedade desde o surgimento da humanidade, quando era utilizada a queima de lenha para a produção de energia. De acordo com Cortez et al. (2008) o resíduo vegetal tem sua produção feita na área rural, como efeitos de atividades agrícolas, atividades essas que vem tendo um crescimento significativo no Brasil. Afirma também que a quantidade de resíduos produzidos também sofreu uma ampliação, do qual não se é utilizado completamente causando um alto desperdício desse recurso. Já quando falamos dos resíduos sólidos, Tada et al. (2009) define esses como aqueles que se encontram nos estados sólido e semissólido, consequência de atividades de origem industrial, doméstica, hospitalar, comercial, agrícola, de serviços e de varrição. É considerada a maior produção de resíduos no mundo, já que abrange o consumo exagerado da população. Segundo Gunther (2008), alguns desses resíduos são prejudiciais à saúde, necessitando de tratamentos adequados, trazendo como problema o alto custo para se executar o tratamento recomendado nesses casos. O saneamento ambiental é um recurso básico para combater esse problema. Os resíduos industriais são analisados como originários dos benefícios vindos de produtos agrícolas e florestais, do uso de carvão vegetal no setor siderúrgico de ferro-gusa e aço e do gás de alto-forno a carvão vegetal (CORTEZ et al., 2008).

Algumas indústrias madeireiras tem a produção de resíduos de acordo com o beneficiamento de toras. Esses resíduos produzidos equivalem às cascas, cavaco, costaneira, pó de serra, maravalha e aparas. Já nas indústrias de alimentos os resíduos são produzidos na fabricação de sucos e aguardentes, tendo benefícios na produção de grãos como arroz, trigo entre outros. Os resíduos animais são determinados pela produção de excrementos das criações de animais. As criações mais importantes para a geração de resíduos nas atividades biológicas é as criações de bovino, suíno, caprino e ovino (CORTEZ et al., 2008). Os resíduos florestais são constituídos por todos os rejeitos que foram deixados para trás na coleta da madeira em florestas, bosques naturais e reflorestamento esses resíduos deixados no local de coleta são as folhas, os galhos e o material resultante da destoca (CORTEZ et al., 2008).

A serragem e aparas produzidas no processamento da madeira são considerados resíduos florestais, em uma cadeia produtiva de serrados formam-se de $7 \%$ de casca, $10 \%$ serragem e $28 \%$ pedaços, sendo que há uma quantidade significativa de perda no processo de extração da madeira, o que não impede que uma grande parte de resíduos de madeira se concentre em serrarias. Somando esses resíduos com os derivados de processamento industrial e da exploração florestal sustentável em todo o Brasil, pode-se obter uma quantidade considerável de resíduos florestais (CORTEZ et al., 2008). 
A biomassa é usada como base na produção de energia em caldeira ou gerador de vapor, executando a decomposição de resíduos orgânicos e gerando energia por meio de uma troca térmica entre combustível e água, fazendo com que a água se aqueça suficientemente para que haja uma transformação do estado liquida para o gasoso. Hoje em dia esse recurso vem sendo utilizado em várias áreas como fabricas de alimentos, curtumes, frigoríficos, indústrias entre outros.

Pode-se classificar a caldeira em dois tipos, sendo elas: Flamotubulares: Nesse tipo de caldeira, os gases quentes passam por tubos que estão inertes na agua a ser aquecida e evaporada. Esses tubos são montados com feixes de permutadores de calor. Esse tipo de caldeira normalmente são utilizadas para pequenas capacidades e para se obter apenas vapor saturado de baixa pressão; Aquotubulares: Já nesse outro tipo de caldeira, que é o mais utilizado, tem a movimentação de agua por dentro dos tubos que são envolvidos pelos gases quentes. São utilizadas em instalações de porte maior com a obtenção de vapor superaquecido, considerado assim de maior importância.

Essas caldeiras produzem cinzas com a queima das biomassas, onde Cacuro et al. (2015) afirma que as cinzas tem uma composição heterogênea sendo observada tanto em sua morfologia, onde se encontra partículas de diversas formas e tamanhos, como em sua composição química, tendo variações dos parâmetros do processo de incineração, processos esses que seria o tipo de biomassa incinerada, tempo de queima e a temperatura. Segundo Cacuro et al. (2015), as características das cinzas que são obtidas de biomassas diferentes ou de um mesmo tipo de biomassa, mas com parâmetros de queima diferenciados, pode sofrer uma variação o que consequentemente altera também sua eficiência nas diferentes aplicações. A cinza produzida pela biomassa pode ser utilizada como corretivo do solo, incorporação de cinza ao solo aumentou os teores de nutrientes em plantações de Eucaliptos, consequentemente levou a um aumento do material orgânico do solo e uma melhor retenção de água, melhorando a característica dos solos quando são misturado 50 toneladas de cinzas por hectare plantada de Eucalyptus (BELLOTE, 1998).

A incorporação dessas cinzas poderia trazer alterações na estrutura físico-mecânica da cerâmica vermelha, que é definida como produtos que tem como sua caracterização a cor avermelhada, como tijolos, blocos, telhas, tubos, lajes para forro, lajotas, vasos ornamentais, agregados leves de argila expandida e outros. Para a produção da cerâmica vermelha, a matéria-prima de maior utilização é basicamente a argila comum, que tem sua obtenção uma boa composição de plasticidade e fusibilidade, o que facilita seu manejo e alcançando uma boa resistência mecânica durante sua queima (KAWAGUTI, 2004). Conforme Teixeira (2006) as indústrias de cerâmica no brasil, teve um grande crescimento de maneira rápida, tornando o Brasil o terceiro maior produtor de material cerâmico do mundo. Isso se deve a grande quantidade de matériaprima natural, diversas fontes alternativas de energia e a tecnologia pratica encontrada nas indústrias. Assim a cerâmica vermelha se encontra como um dos nove segmentos neste setor industrial.

Em sua área comercial, pode-se classificar como produtos de maior negociação no mercado de cerâmica vermelha são os blocos de vedação, tijolos, telhas, tubos, ladrilhos, elementos vazados e outros (TEIXEIRA, 2006). As indústrias de cerâmica são consideradas grandes utilizadoras de resíduos sólidos, fazendo com que esses resíduos se encontre em destinos que traga benefícios ao meio ambiente, evitando 
assim o aumento da poluição. As propriedades de cerâmicas são determinadas de acordo com os materiais que os compõem, podendo controlar suas características com uma seleção adequada de sua matéria-prima (VIEIRA, 2006).

De acordo com Vieira (2006), com o seu alto nível de produção a indústria de cerâmica vermelha é considerada uma produção ecologicamente correta, pois se reaproveita vários tipos de resíduos, o que possibilita o consumo de uma grande quantidade de rejeito. Uma das vantagens encontrada no processo produtivo é a melhoria e a redução do consumo de combustível na queima incorporação de rejeitos indústrias na cerâmica.

Ao realizar uma incorporação de um tipo de resíduo não inerte em cerâmica, devido ao processo de sinterização, pode desencadear algumas reações, por exemplo a valorização dos componentes perigosos, mudança de composição do material e inertização dos componentes potencialmente tóxicos através de sua fixação na fase vítrea possibilitando em alguns casos a extinção da toxidade do mesmo. Vários resíduos são utilizados na indústria cerâmica, como os resíduos de mineração, indústria de papel, estação de tratamentos de água e esgoto, petrolíferos, siderúrgicos, entre outros (VIEIRA, 2006).

\section{METODOLOGIA}

Esta pesquisa é de caráter experimental determinando-se como objetos de estudo a Massa específica aparente, Retração linear de queima, Absorção de água, Tensão de ruptura à compressão e microestrutura da cerâmica, selecionando-se as variáveis de porcentagem de cinzas incorporada que seria capaz de influenciar os resultados nos objetos de estudo. Foi realizado no laboratório de materiais da construção e laboratório de química da Faculdade Presidente Antônio Carlos, Instituto Tocantinense Presidente Antônio Carlos, Porto Nacional, no laboratório de química do Instituto Federal do Tocantins, Porto Nacional e no laboratório de Materiais Compósitos-UFT.

\section{Amostragem}

Para realização deste trabalho foram utilizadas como matérias-primas uma massa argilosa já caracterizada (Lima, 2016) e empregada para fabricação de cerâmica vermelha procedente da região de Porto Nacional, Tocantins, e cinzas, resíduo do processo de queima da caldeira de biomassade lenha originada de eucalipto e madeira do serrado. Foram analisados quatros composições com incorporação da cinza na massa argilosa nos seguintes percentuais: 5, 10, 15 e 20 \% em peso com referência ao branco, para cada composição determinada, foram confeccionadas 14 corpos de prova para os ensaios laboratoriais. Estas composições serão homogeneizadas de acordo com a viabilidade de misturas dos resíduos por 30 minutos.

\section{Preparo dos corpos de prova}

Os corpos de provas foram preparados seguindo os protocolos descritos por (ASTM, 1972; BORLINI, 2006; PINHEIRO, 2008). Os corpos de prova retangulares foram conformados por prensagem uniaxial a 20 MPa nas dimensões $114 \times 25 \times 10 \mathrm{~mm}$. Os corpos de prova foram inicialmente secos a temperatura ambiente 
até peso constante (aproximadamente 72 hs). Para análise da influência da porcentagem de incorporação da cinza, a queima foi em mufla de laboratório às temperatura de $900^{\circ} \mathrm{C} \mathrm{com} \mathrm{taxa} \mathrm{de} \mathrm{aquecimento} \mathrm{de} 3^{\circ} \mathrm{C} / \mathrm{min}$ e isoterma de 120 min na temperatura de patamar. O resfriamento foi por convecção natural, desligando-se o forno.

\section{Propriedades Físico-mecânicas}

As propriedades Físico-mecânicas foram determinadas através de ensaios padronizados com densidade aparente a seco e de queima e absorção de água utilizado as normas Americanas (ASTM C373-72, 1972), retração linear como não é um teste exigido pelas normas Brasileira, Americanas ou Europeias seguimos o procedimento descrito segundo BORLINI (2006). O ensaio de resistência à compressão para os corpos de provas foi adequado à norma NBR 7222-94 (ABNT, 1994).

\section{Análise dos dados}

Os resultados foram avaliados com ajudas de métodos estatístico do tipo descritivo simples com uso de gráficos e tabelas, feitos através do Software Excel o GraphPadPrism 4.0 Software Inc. (San Diego, CA, EUA), com nível de significância foi estabelecido em $p<0,05$.

\section{RESULTADOS E DISCUSSÕES}

A cinza utilizada na mistura com argila foi analisada o pH que apresenta determinando-se para uma amostra de concentração de $1 \mathrm{~g} / \mathrm{L}$ estando em 6,96 . Na preparação dos corpos de provas foi analisada a forma de mistura, sendo a mistura direta de cinza com a argila, após homogeneização total inicia-se a adição de água até obter uma massa com característica plástica

No processo de queima, dentro da mufla, não foi observada a quebra espontânea dos corpos preparados, evidenciando que a preparação das massas argilosa com cinzas estão homogenias. Após a etapa de queima os corpos-de-prova foram divididos em dois grupos, o primeiro grupo para teste de absorção de água e o segundo para ensaio de resistência à compressão. A tabela 1 mostra os resultados obtidos de massa aparente a seco e após a queima para os corpos de prova feito com adição de0,5, 10, 15 e 20\% de cinzas e 120 minutos de queima a $900^{\circ} \mathrm{C}$ com os valores da média, desvio padrão e coeficiente de variação.

Tabela 1: Resultado da massa especifica aparente antes e após a queima.

Porcentagem de adição de cinzas

Massa específica aparente antes da queima $\left(\mathrm{g} / \mathrm{cm}^{3}\right)$

\begin{tabular}{|l|l|l|l|l}
\hline $0 \%$ & $5 \%$ & $10 \%$ & $15 \%$ & $20 \%$ \\
\hline 2,40 & 1,90 & 2,00 & 1,70 & 1,70 \\
\hline 2,10 & 1,80 & 1,90 & 1,80 & 1,80 \\
\hline 2,20 & 1,80 & 2,10 & 2,10 & 1,70 \\
\hline 2,10 & 1,80 & 2,00 & 1,90 & 1,70 \\
\hline 2,10 & 1,80 & 1,90 & 1,70 & 1,70 \\
\hline 2,20 & 1,90 & 2,00 & 1,90 & 1,80 \\
\hline 2,10 & 1,90 & 1,90 & 1,80 & 1,80 \\
\hline 2,10 & 1,90 & 1,80 & 1,90 & 1,80 \\
\hline 2,20 & 2,00 & 1,90 & 1,90 & 1,90 \\
\hline 2,20 & 1,90 & 2,10 & 2,00 & 1,80 \\
\hline 2,10 & 1,90 & 2,00 & 2,00 & 1,60 \\
\hline \multicolumn{5}{|l}{}
\end{tabular}




\begin{tabular}{|c|c|c|c|c|c|}
\hline & 2,10 & 1,60 & 1,90 & 2,10 & 1,70 \\
\hline & 2,20 & 1,80 & 1,80 & 1,70 & 1,70 \\
\hline & 2,30 & 2,00 & 1,70 & 2,00 & 1,80 \\
\hline Media & 2,17 & 1,86 & 1,93 & 1,90 & 1,76 \\
\hline Desvio $\mathrm{P}$ & 0,08 & 0,10 & 0,11 & 0,13 & 0,08 \\
\hline Coef. Var & 0,04 & 0,05 & 0,06 & 0,07 & 0,05 \\
\hline \multirow{14}{*}{ Massa específica aparenteapós a queima $\left(\mathrm{g} / \mathrm{cm}^{3}\right)$} & 2,35 & 1,91 & 1,66 & 1,34 & 1,15 \\
\hline & 2,18 & 2,08 & 1,76 & 1,25 & 1,05 \\
\hline & 2,27 & 1,8 & 1,68 & 1,37 & 1,23 \\
\hline & 2,43 & 1,77 & 1,76 & 1,29 & 1,18 \\
\hline & 2,28 & 2,12 & 1,77 & 1,46 & 1,21 \\
\hline & 2,4 & 2,08 & 1,87 & 1,35 & 1,16 \\
\hline & 2,07 & 1,98 & 1,77 & 1,33 & 1,23 \\
\hline & 2,28 & 2,09 & 1,54 & 1,42 & 1,2 \\
\hline & 2,32 & 2,04 & 1,62 & 1,3 & 1,3 \\
\hline & 2,46 & 1,99 & 1,74 & 1,47 & 1,27 \\
\hline & 2,29 & 2,24 & 1,52 & 1,42 & 1,18 \\
\hline & 2,49 & 1,68 & 1,72 & 1,49 & 1,26 \\
\hline & 2,33 & 1,97 & 1,79 & 1,4 & 1,24 \\
\hline & 2,1 & 1,95 & 1,71 & 1,41 & 1,23 \\
\hline Media & 2,3 & 1,98 & 1,71 & 1,38 & 1,21 \\
\hline Desvio $\mathrm{P}$ & 0,12 & 0,15 & 0,1 & 0,07 & 0,06 \\
\hline Coef. Var & 0,05 & 0,08 & 0,06 & 0,05 & 0,05 \\
\hline
\end{tabular}

Na Tabela1 é possível observar que a massa especifica aparente dos corpos de provas a seco para a diferente porcentagem de cinzas, apresenta pouca variação quando comparamos as medias deles pelo método de teste paramétrico de $T$-student com índice de significaria ( $\alpha$ ) de $5 \%$ obtemos os valores de T sendo que a amostra com $0 \%$ de cinzas tem a maior massa especifica aparente antes da queima que os demais corpos de provas, os corpos de provas com as adições de 5, 10 e 15\% de cinzas tem massas especifica aparente com médias estatisticamente iguais e o de menor massa especifica aparente antes a queima foi o de $20 \%$ de cinzas (Figura 1).

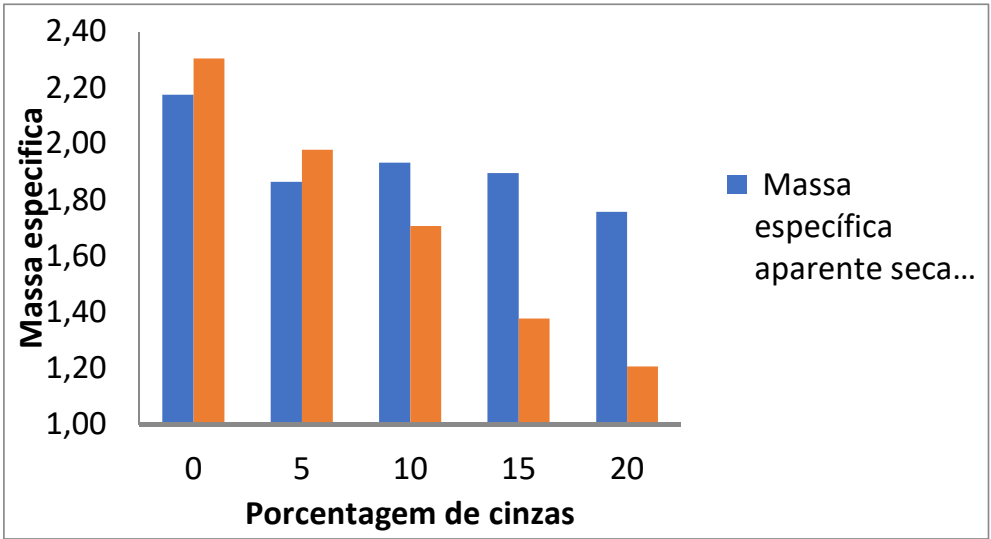

Figura 1: Gráfico da massa especifica aparente a seco e de queima a $900^{\circ} \mathrm{C}$ da massa cerâmica com diferente porcentagem de cinza.

Observa-se também (Figura1) que com o aumento da porcentagem de cinzas, houve decréscimo nos valores de massa específica aparente após a queima, decorrentes da evaporação da fase líquida no interior da amostra e a densidade menor da cinza comparado com a argila, na comparação das medias usando o teste de $T$-student mostra que as médias são todas diferentes entre elas.

O ensaio de retração linear não é um parâmetro normatizado pelas normas brasileiras para classificação cerâmica, mas é um importante parâmetro e pode ser considerado na análise. Estudos 
anteriores (BORLINI, 2002) correlaciona a porosidade da cerâmica com a retração linear. Cerâmicas porosas apresentam, de forma geral, retração linear na ordem de 3\%; Cerâmicas semiporosa apresentam, de forma geral, retração linear na ordem de 4-6\%; Cerâmicas pouca porosa (gresificada) apresentam, de forma geral, retração linear na ordem de $8 \%$. A Tabela 2 mostra os resultados da retração linear após a queima dos corpos de prova com adição de 0,5, 10, 15 e 20\% de cinzas com os valores de média, desvio padrão e coeficiente de variação.

Tabela 2: Resultado do experimento de Retração linear da queima.

\begin{tabular}{|c|c|c|c|c|c|}
\hline \multicolumn{6}{|l|}{ Porcentagem de adição de cinzas } \\
\hline \multirow{15}{*}{ Retração linear de queima (\%) } & $0 \%$ & $5 \%$ & $10 \%$ & $15 \%$ & $20 \%$ \\
\hline & $3,88 \%$ & $4,00 \%$ & $5,66 \%$ & $5,61 \%$ & $7,27 \%$ \\
\hline & $3,92 \%$ & $7,84 \%$ & $7,55 \%$ & $4,72 \%$ & $5,45 \%$ \\
\hline & $5,77 \%$ & $6,12 \%$ & $6,67 \%$ & $-0,20 \%$ & $5,50 \%$ \\
\hline & $5,88 \%$ & $8,00 \%$ & $6,67 \%$ & $4,67 \%$ & $7,27 \%$ \\
\hline & $4,95 \%$ & $6,06 \%$ & $6,73 \%$ & $6,48 \%$ & $5,50 \%$ \\
\hline & $3,88 \%$ & $7,84 \%$ & $3,88 \%$ & $6,36 \%$ & $5,50 \%$ \\
\hline & $3,92 \%$ & $6,86 \%$ & $6,60 \%$ & $4,67 \%$ & $5,56 \%$ \\
\hline & $4,00 \%$ & $6,86 \%$ & $5,71 \%$ & $3,77 \%$ & $6,54 \%$ \\
\hline & $5,00 \%$ & $7,84 \%$ & $4,76 \%$ & $5,56 \%$ & $5,66 \%$ \\
\hline & $4,95 \%$ & $7,77 \%$ & $4,85 \%$ & $5,66 \%$ & $7,34 \%$ \\
\hline & $5,88 \%$ & $6,86 \%$ & $2,91 \%$ & $4,63 \%$ & $7,27 \%$ \\
\hline & $4,95 \%$ & $6,86 \%$ & $7,62 \%$ & $4,67 \%$ & $7,34 \%$ \\
\hline & $4,95 \%$ & $6,93 \%$ & $3,88 \%$ & $5,50 \%$ & $7,34 \%$ \\
\hline & $2,91 \%$ & $7,92 \%$ & $4,81 \%$ & $4,67 \%$ & $5,56 \%$ \\
\hline Media & $4,63 \%$ & $6,98 \%$ & $5,59 \%$ & $4,77 \%$ & $6,37 \%$ \\
\hline Desvio P & $0,90 \%$ & $1,08 \%$ & $1,45 \%$ & $1,61 \%$ & $0,89 \%$ \\
\hline Coef. Var & 0,19 & 0,15 & 0,26 & 0,34 & 0,14 \\
\hline
\end{tabular}

O efeito do resíduo cinza na retração linear da cerâmica indica que poderíamos estar com corpos de prova semiporoso, já que os valores obtidos estão entre 4 e 7\%. A comparação das medias usando o teste de T-student mostra que os valores de adição de 5 e $20 \%$ de cinzas tem médias estatisticamente iguais e os corpos de prova com adição de 10 e 15\% de cinzas apresenta medias de retração linear estatisticamente iguais. A Figura 2 apresenta a retração linear da massa cerâmica em função da porcentagem de cinzas, observa-se que ocorre uma variação deste parâmetro com o aumento da porcentagem de cinzas.

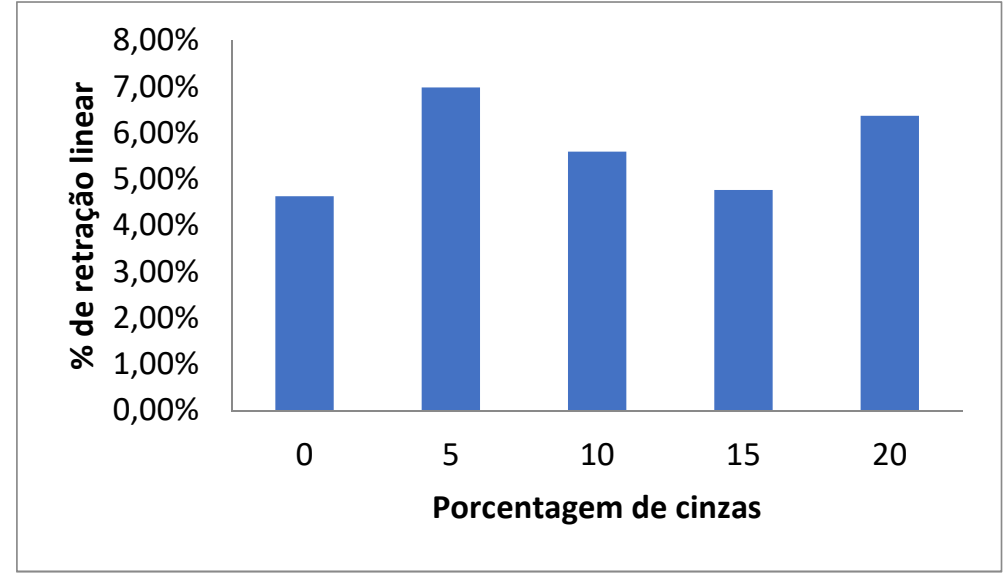

Figura 2: Gráfico de retração linear após queima a $900^{\circ} \mathrm{C}$ da massa cerâmica com diferente porcentagem de cinza.

Os estudos de correlação da porosidade com a retração linear não tem em conta a diminuição do diâmetro dos poros e sim a diminuição da quantidade de poros pelo que podemos ter corpos de provas com 
uma quantidade elevada de poros de diâmetros pequenos e uma retração linear significativa que pode ser analisada com o ensaio de absorção de água da massa cerâmica em função do tempo de queima (Tabela 3).

Tabela 3: Resultado do experimento de absorção de água nos corpos de prova.

\begin{tabular}{|c|c|c|c|c|c|}
\hline \multicolumn{6}{|c|}{ Porcentagem de adição de cinzas } \\
\hline \multirow{8}{*}{ Absorção de água (\%) } & $0 \%$ & $5 \%$ & $10 \%$ & $15 \%$ & $20 \%$ \\
\hline & $18,23 \%$ & $23,05 \%$ & $25,00 \%$ & $43,95 \%$ & $54,93 \%$ \\
\hline & $14,25 \%$ & $23,04 \%$ & $24,72 \%$ & $46,76 \%$ & $58,55 \%$ \\
\hline & $13,35 \%$ & $22,64 \%$ & $24,81 \%$ & $44,24 \%$ & $56,69 \%$ \\
\hline & $13,07 \%$ & $23,55 \%$ & $26,04 \%$ & $43,59 \%$ & $55,64 \%$ \\
\hline & $13,11 \%$ & $22,14 \%$ & $25,34 \%$ & $45,05 \%$ & $55,12 \%$ \\
\hline & $13,61 \%$ & $21,55 \%$ & $27,57 \%$ & $50,33 \%$ & $41,77 \%$ \\
\hline & $15,34 \%$ & $21,80 \%$ & $27,69 \%$ & $46,94 \%$ & $51,56 \%$ \\
\hline Media & $14,42 \%$ & $22,54 \%$ & $25,88 \%$ & $45,84 \%$ & $53,46 \%$ \\
\hline Desvio $\mathrm{P}$ & $1,86 \%$ & $0,73 \%$ & $1,27 \%$ & $2,38 \%$ & $5,57 \%$ \\
\hline Coef. Var & 0,13 & 0,03 & 0,05 & 0,05 & 0,10 \\
\hline
\end{tabular}

Observa-se na Figura 3 um aumento expressivo da absorção de água dos corpos de prova com o aumento da porcentagem de cinza adicionada à argila, na comparação das medias usando o teste de $T$ student mostra que os valores das médias são todos diferentes sendo a de maior absorção a de $20 \%$ de cinza, classificando-os como cerâmica porosa os corpos de provas desde 5 até $20 \%$, contrário da classificação pouco poroso obtido na análise dos resultados de retração linear.

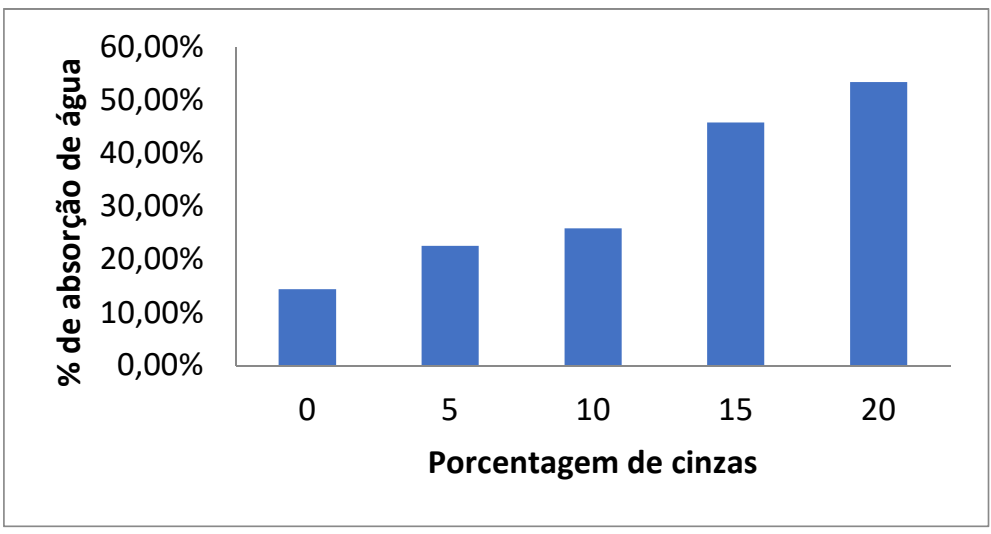

Figura 3: Gráfico de absorção de água após queima a $900^{\circ} \mathrm{C}$ da massa cerâmica com diferente porcentagem de cinza.

A absorção de água sempre está relacionada com a porosidade aberta do material, este resultado indica a presencia de poros abertos com diâmetro considerado para permitir a entrada de moléculas de água no interior do corpo de prova, comprometendo sua resistência ao ensaio de ruptura. A Tabela 4 mostra os resultados dos ensaios de resistência mecânica à compressão após a queima dos corpos de prova a diferentes tempos de queima com os valores de média, desvio padrão e coeficiente de variação.

Observa-se na figura.4 uma diminuição da resistência mecânica da massa argilosa quando aumenta a porcentagem de cinza dos corpos de prova. Na comparação das medias usando o teste de T-student mostra que os valores das médias da resistência à compressão são estatisticamente diferentes chegando a ser nula os valores de resistência para 15 e 20\% de cinza na mistura com argila. A resistência mecânica à compressão diminui com aumento da porcentagem incorporada de cinza na massa argilosa, ficando inviável o uso de porcentagem igual ou superior a $15 \%$ de cinzas. 
Tabela 4: Resultado do experimento de Resistência mecânica à compressão nos corpos de prova.

\begin{tabular}{l|l|l|l|l|l}
\hline Porcentagem de adição de cinzas & \multicolumn{1}{l}{$\mathbf{1 5 \%}$} & $\mathbf{2 0 \%}$ \\
\hline & $\mathbf{0 \%}$ & $\mathbf{5 \%}$ & $\mathbf{1 0 \%}$ & $\mathbf{1 5 \%}$ \\
\cline { 2 - 6 } & 10,88 & 8,10 & 2,90 & 0,01 & 0,01 \\
\cline { 2 - 6 } Resistência à compressão (Mpa) & 9,66 & 4,70 & 3,70 & 0,01 & 0,01 \\
\cline { 2 - 6 } & 9,81 & 8,50 & 3,70 & 0,01 & 0,01 \\
\cline { 2 - 6 } & 14,65 & 11,80 & 4,30 & 0,02 & 0,01 \\
\cline { 2 - 6 } & 10,82 & 4,70 & 4,50 & 0,02 & 0,00 \\
\cline { 2 - 6 } & 12,65 & 7,80 & 4,60 & 0,01 & 0,01 \\
\hline media & 14,37 & 5,70 & 3,70 & 0,02 & 0,01 \\
\hline desvio P & 11,83 & 7,31 & 3,91 & 0,01 & 0,01 \\
\hline Coef. Var & 2,07 & 2,54 & 0,62 & 0,01 & 0,01 \\
\hline
\end{tabular}

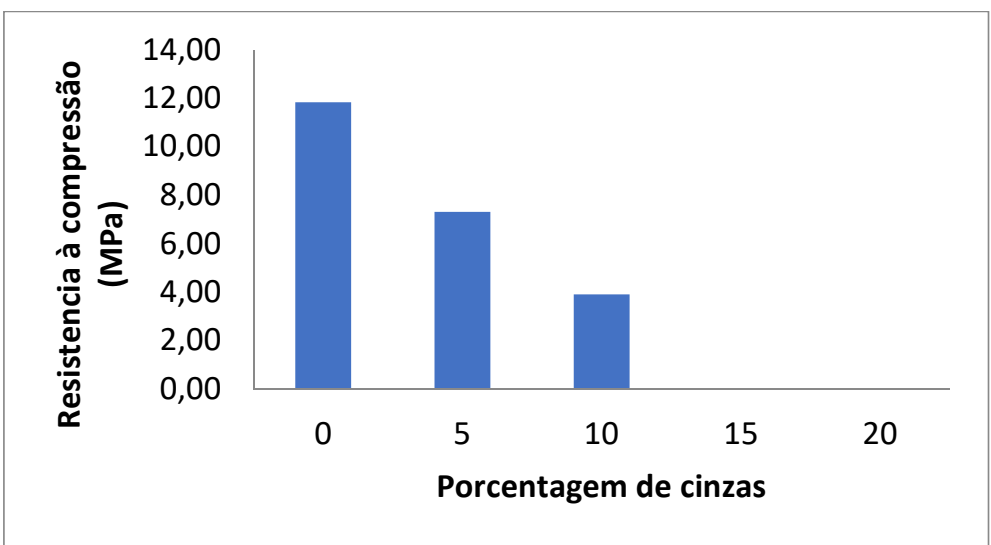

Figura 4: Gráfico de resistência à compressão após queima a $900^{\circ} \mathrm{C}$ da massa cerâmica com diferente porcentagem de cinza.

\section{CONCLUSÕES}

A influência da incorporação de cinzas da caldeira de biomassa nas propriedades físicas e mecânicas de uma massa argilosa queimada a $900^{\circ} \mathrm{C}$, foi observado que aumento da porcentagem de cinzas na massa argilosa ocasionou uma piora do desempenho técnico dos corpos de prova de cerâmica vermelha, com diminuição da massa especifica após queima, aumento da absorção de água e decréscimo da resistência mecânica. A massa especifica aparente a seco da cerâmica foi menor devido à baixa massa especifica da cinza empregada e presencia de material orgânico que não queimou, acarretando um menor empacotamento e aumento da porosidade do material.

\section{REFERÊNCIAS}

ABNT. Associação Brasileira de Normas Técnicas. NBR 7222: Argamassa e concreto - Determinação da resistência à tração por compressão. 1994

ASTM. American Society for Testing and Materials, Water Absorption, BulkDensity, Apparent Porosity, and Apparent Specific Gravity of Fired Whiteware Products. C 373-72. 1972.

BELLOTE, A. F. J.; SILVA, H. D.; FERREIRA, C. A.; ANDRADE, G. C.. Resíduos da indústria de celulose em plantios florestais. Boletim de Pesquisa Florestal, n.37, p.99-106, 1998.

BORLINI, M. C.. Incorporação de cinza de bagaço de cana de açucarem massa cerâmica argilosa. In: INIVERSIDADE
ESTADUAL DO NORTE FLUMINENSE DARCYRIBEIRO-UENF. Anais. Campo Dos Goytacazes, 2006.

CALLISTER W. D.. Materials Science and Engineering: An Introduction. 7 ed. New York: John Wiley \& Sons, Inc. 2007.

CORTEZ, L. A. B.; LORA, E. S.; GÓMEZ, E. O.. B521 Biomassa para energia Electo. Campinas: Unicamp, 2008.

CACURO, T. A.; WALDMAN, W. R.. Artigo Cinzas da Queima de Biomassa: Aplicações e Potencialidades Rev. Virtual Quim., v.7, n.6, p.2154-2165, 2015.

FIGUEIREDO, F. L.. Avaliação de uma unidade autônoma de produção de energia elétrica composta por sistema de gaseificação concorrente e grupo gerador com capacidade 
de 50 kVA. Dissertação (Mestrado em engenharia de edificações e saneamento) - Universidade Estadual de Londrina, Londrina, 2012.

GUNTHER, W. M. R.. Resíduos Sólidos no Contexto da Saúde Ambiental. Universidade de São Paulo Faculdade de Saúde Pública. São Paulo, 2008.

KAWAGUTI, W. M.. Estudo do Comportamento Térmico de Fornos Intermitentes Tipo 'Paulistinha' Utilizados na Industria de Cerâmica Vermelha. Dissertação (Mestrado em Engenharia Mecânica) - Universidade Federal de Santa Catarina, Florianópolis, 2004.

LIMA D. P.. Caracterização de lodo da estação de tratamento de agua utilizado como agregado na construção civil em elementos de telhas vermelhas. 2016.

LUCAS, D.; BENATTI, C. T.. Argilosos empregados na construção civil. In Utilização de Resíduos Industriais para a Produção de Artefatos. Maringá, 2008.
MENEZES, R. R.; NEVES, G. A.; FERREIRA, H. C.. O estado da arte sobre ouso de resíduos como matérias-primas cerâmicas alternativas. Revista Brasileira de Engenharia Agrícola e Ambiental, Campina Grande, v.6, n.2, p.303-313, 2002.

PARENTE, E. J.. Biodiesel: uma aventura tecnológica num país engraçado. Fortaleza: TECBIO, 2003.

PINHEIRO, B. C. A.; HOLANDA, J. N. F.. Efeito da temperatura de queima em algumas propriedades mecânicas de cerâmica vermelha. Cerâmica, v56, n.339, p.237-243, 2008.

TEIXEIRA, S. R.. Caracterização de Argilas Usadas Para Produção de Cerâmica Vermelha e Estudo Das Alterações Nas Suas Propriedades Pela Adição de Resíduos Sólidos. Tese (Doutorado) - Universidade Estadual Paulista, Faculdade de Ciências e Tecnologia, 2006.

VIEIRA, C. M. F.; MONTEIRO, S. N.. Cerâmica Argilosa Incorporada com Resíduo Oleoso Proveniente do Setor Petrolífero. Revista Matéria, v.11, n 3, p 217-222, 2006.

A CBPC - Companhia Brasileira de Produção Científica (CNPJ: 11.221.422/0001-03) detém os direitos materiais desta publicação. Os direitos referem-se à publicação do trabalho em qualquer parte do mundo, incluindo os direitos às renovações, expansões e disseminações da contribuição, bem como outros direitos subsidiários. Todos os trabalhos publicados eletronicamente poderão posteriormente ser publicados em coletâneas impressas sob coordenação da Sustenere Publishing, da Companhia Brasileira de Produção Científica e seus parceiros autorizados. Os (as) autores (as) preservam os direitos autorais, mas não têm permissão para a publicação da contribuição em outro meio, impresso ou digital, em português ou em tradução. 